\title{
THE INFLUENCE OF LANGUAGE COMPETENCE, WRITING COMPETENCE, AND CULTURAL COMPETENCE ON PRODUCING A SUCCESSFUL WRITING
}

Hermanto

\begin{abstract}
:
Writing is a skill derived from a long way of learning and exercises. Different from other language skills, writing is considered the difficult language skill to acquire since it involves many aspects of linguistics, social, and writing knowledge and conventions. There are at least three important elements of writing useful to produce a good piece of composition, language competence, writing competence and cultural competence. This paper shows the influence of these three elements in order to produce good, readable, communicative, and successful writing.
\end{abstract}

Key words: language competence, writing competence, cultural competence, writing skill, successful writing.

When we learn a second language, we learn to communicate with other people with the language we are learning. We talk to them, understand them, read what they have written and write to them. This kind of activities also happens in our daily life with our first language. Especially in this era when information is so abundantly available and easily accessed, we need to read and respond or comment directly orally or indirectly in the form of writing. Therefore, reading, speaking, and writing skills must be mastered by people as part of literate and modern society in order to deal with complex intellectual and social tasks.

But what happen in real life situation? Do people have sufficiently equal speaking, reading, and writing competence? According to some experts, among the four language skills (listening, speaking, reading, and writing), writing is considered as the language skill which is difficult to acquire. Although both speaking and writing are productive modes of language skill, but they are, to some great extent, different. Speaking has started as soon as human wants to build relationships with others, while writing generally start when people enter formal education, in which writing activity occurs under some kind of purposive instruction. Moreover, learning to write is not just a question of developing a set of mechanical 'orthographic' skill. According to Tribble (1996), it also involves 
learning a new set of cognitive and social relations . Nobody denies that writing is important in many aspects of life. In educational context, for example, writing can be an important tool for increasing the educational achievement of people since writing is a central aspect of real learning, or education in its truest sense. Graves (1978) in Whiteman (1981) believes that when people read or listen, they take in and process information. When they write, they must analyze and synthesize information. Another advantage of being able to write is that it makes it possible for individuals to take on social roles which are mostly denied to those who do not have this skill. Even now in global and competitive job market, being able to write in second/foreign language will certainly give someone additional value and greater chance of access to the professional and commercial opportunities.

The question that may come up concerning this matter is how to be a skilful writer. In other words, how we can produce a successful piece of writing. What kind of competence a person must have in order to be able to write successfully. The answer to these problems must be various due to different purposes, types of writing and the level of learners. Nevertheless, there are at least three kinds of competence that must be acquired by someone who wants to be able to produce effective writing. These kinds of competence are language competence, writing competence, and cultural competence. These competencies are not implemented all at once in the writing process. Rather it depends on the level of the learner. One competence is more suitable to learn than the other. For example, for beginner, language competence is more appropriate to give earlier than cultural competence. As the learner gets more advanced, he should learn more complex skills.

\section{Language Competence}

Before going deeper into this topic, I would like to clarify what is meant by language competence because, in my opinion, the idea of being competent in a language depends on the person's interest and reasons for developing it. Being competent in a language may refer to either having speaking proficiency, foreign language literacy, cross-cultural awareness or knowledge about language. In this 
paper, what is meant by language competence is the ability relating to the knowledge about language and its use.

One of the best known models of language ability is known as “communicative competence". This model was developed to account for the kinds of knowledge people need in order to use language in meaningful interaction. This term was originally coined by anthropologist Dell Hymes as a means of describing the knowledge language users need in addition to the grammatical forms of the language. The term was then adopted by the language teaching community after it had been developed into a model for that field by Michael Canale and Merrill Swain (1980), then by Sandra Savignon (1997).

This model includes four components: (a) grammatical competence, the ability to use the forms of the language (sounds, words, and sentence structure), (b) discourse competence, the ability to understand and create forms of the language that are no longer than sentences, such as stories, conversations, or business letters. It includes understanding how particular instances of language use are internally constructed. Discourse competence also includes understanding how texts relate to the context or situation in which they are used, (c) sociolinguistic competence, the ability to use language appropriately in different context. It is our sociolinguistic competence that allows us to be polite according to the situation we are in and to be able to infer the intentions of others, (d) strategic competence, the ability to compensate for lack of ability in any of the other areas. Language learners who really need to communicate in their adopted language tend to develop a number of strategies for making themselves clear in spite of their incomplete knowledge.

Another different concept of language competence is described by Bachman (1990) as shown in Brown (1994: 229). Bachman broadly divides language competence into two, organizational competence and pragmatic competence, which is further divided into smaller competences as shown in the following diagram 1 : 


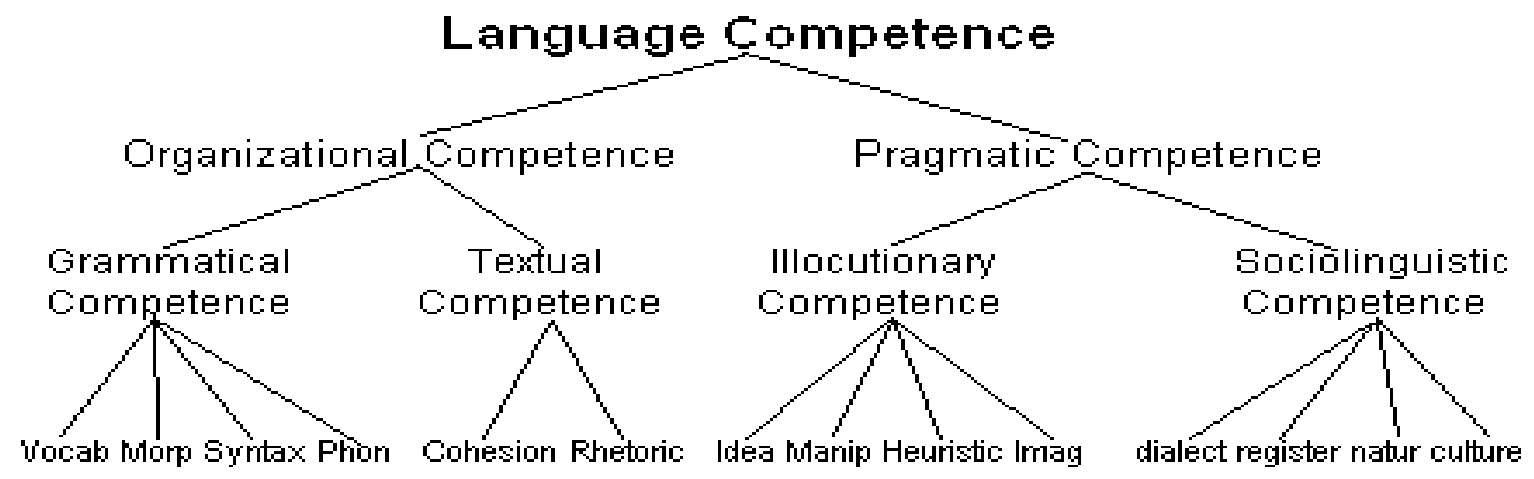

Diagram 1. Bachman's division of language competence (Bachman, 1990, in Brown, 1994:229).

From the diagram we can see that organizational competence which refers to the ability to arrange morpheme, words, and sentences in order to make meaning, is divided into two smaller competences, grammatical competence and textual competence respectively. Grammatical competence is the ability to organize language on the sentence level. It comprises four elements, namely vocabulary, morphology, syntax, and phonology. Vocabulary is all the words and lexical items of a language and their meanings. It could be one word or several words that combine to have one collective meaning. Morphology is the study of the structure of words of a language via the study the morpheme of a language and how the morphemes come together to form words. Syntax deals with the proper order of words in a sentence. Phonology is concerned with the study of the sounds of a language.

Textual competence which is defined as the ability to organize language on the composition level includes cohesion and rhetoric. Cohesion deals with sentence cohere (stick together) in logical order, while rhetoric is the science of persuasive speaking.

The second branch of language competence is pragmatic competence, the ability to use language in socially appropriate ways. It is divided into illocutionary competence and sociolinguistic competence. Illocutionary competence contains ideational function, manipulative function, heuristic function, and imaginative 
function. Ideational function is the function of language to express one's ideas. Manipulative function is the function of language to get someone to do what you would like him/her to do. Heuristic function is the function of language to solve problems, especially by trial-and-error method, and imaginative function is the function of language to express imaginary ideas.

Sociolinguistic competence dealing with the ability of how language is regionally/socially/culturally accepted comprises four aspects, namely dialect (regional or social differences in language), register (considering one's audience and social context), naturalness (staying in the bounds of what is "common" usage of the language), and culture (adhering to cultural expectations when using the language, including figures of speech, proper item and place, etc.).

\section{Writing Competence}

Writing competence refers to the ability to write a good composition which meets the following criteria: (a) Purpose and clarity, the degree to which the students has demonstrated an understanding of the position taken in the article and has established a reasoned response and critical interpretation, (b) Organization, the degree to which the student has produced a unified and coherent composition, (c) Specificity and evidence, the degree to which specific evidence from the article is documented, integrated, and used to support arguments in the student's writing; the degree to which counter arguments are supported through evidence, and (d) Usage, mechanic, and grammar, the degree to which the student has exhibited corrected usage (tense, word choice), spelling, punctuation, and grammar.

In my opinion, this writing competence is much closely deal with writing process, that is knowledge of the most appropriate way of preparing for a writing task. If writer knows what to write in a given context, what the reader expects the text to look like, which parts of the language system are relevant to the particular task in hand, and has a command of writing skills appropriate to this task, then they have a good chance of writing something that will be effective (Tribble, 
1996). In addition, taking good care during writing process will determine the quality of the result of the writing.

Writing process involves cyclic writing activities which move learners from generation of ideas and the collection of data through to the publication of a finished text. According to Gebhard (1996) there are two model of writing process, linier and recursive. Linier process is the simplification of way of thinking, starting from pre-writing, composing, revising and editing as steps that go on one direction process. The writer does not go back to the earlier steps in producing the writing.

In reality, the process is not that straight, but recursive meaning that we go through a process of creating and recreating the piece of writing until we discover and clarify within ourselves what it is that we want to say and until we are able to express this meaning in a clear way. In other words, at any point in the preparation of the text, writer can loop backwards or forwards to whichever of the activities involved in the text composition he finds useful.

\begin{tabular}{|c|c|c|}
\hline Linear model & Recursive model \\
Prewriting & Prewriting & \\
Editing & &
\end{tabular}

Diagram 4. Linear and recursive model of writing process Gebhard (1996)

During prewriting stage, writer is specifying the task, planning and outlining, collecting data and making notes. During revising, the writer is reorganizing, shifting emphasis and focusing information and style for the 
readership, while during editing phase, the writer is checking grammar, lexis, surface features such as punctuation, spelling, layout, quotations, references.

\section{Cultural Competence}

According to Cross et al. (1989) and Isaacs \& Benjamin (1991) in general, cultural competence refers to a set of congruent behaviors, attitudes, and policies that come together in a system, agency, or among professionals and enables that system, agency, or those professionals to work effectively in cross-cultural situations. Having a cultural competence is important to encourage culturally competent and linguistically appropriate exchanges and collaborations among families, professionals, students, and communities.

The word culture is used because it implies the integrated patterns of human behavior that includes thoughts, communications, actions, customs, beliefs, values, and institutions of racial, ethnic, religious, or social groups. The word competence is used because it implies having the capacity to function in a particular way, that is, the capacity to function within the context of culturally integrated patterns of human behavior defined by the group.

From this definition, it is obvious that there is close relation between culture and language especially in language exchange or communication, particularly in writing. To discuss more I start with the assumption that texts themselves are highly culturally contexted. Consequently, it is strongly required that the non-native writer produce texts not only for the discourse community but also for the target culture. In doing so, the writer needs an awareness of the native speaker norms, and an understanding of the values and expectations of the target culture but at the same time needs to be able to integrate his/her own culture with the target culture to produce texts which are satisfying both to the non-native speaker and to the native speaker discourse community.

According to Miller (1998) writing can be viewed as social activity in the sense that writing is an act of communication between writer and reader within an external context. This model is based on the belief that there is shared knowledge (norms or expectations) in the discourse community which affects text 
construction. Accordingly, an act of writing results in the production of texts which conform to the types of texts shared in the community (Widiati, 2006). This notion of text types is generally known as genre.

Moreover, the language use in a community/society is a form of cultural behavior in which texts have their own communicative purpose. As a result, socio-cultural understanding has an important role in determining which text types will be classified as parts of a genre and which genres will be socially valued. Because of this, it does not surprise us that one piece of writing is more acceptable than the other.

According to Malinowski (1960), some experts indicate that genres are socially and culturally significant and have an important function in the maintenance and cohesion of the culture. Oring (1986) adds on that genres are formed by the cultural traditions of the community. In this view, genre is approached not only as text, but also as activity (Shopen, 1993). The implications of these perspectives for the study of texts are that any study of a body of texts must see genre as culturally situated, culturally defined, and culturally defining. Kramsch (1992) adds that texts like other parts of language are cultural activities and the act of writing is an act of encoding culture as much as it is a case of encoding information.

A concern for writing in society has defined writing not as a singular entity, but rather as a plurality. There are different kinds of writing which serve different functions for different group of people at different times. Different kinds of writing are defined in and by varying contexts. In other words, in producing a piece of writing the writer must consider the audience or the readers and the purpose or the reason for writing.

\section{The Influence of Language Competence, Writing Competence, and Cultural Competence on Producing a Good Piece of Writing.}

From the explanation of each of the competence above, we can see that each competence has its own particular role in producing a piece of writing. Language competence, which concerns more with linguistic elements of language, 
together with writing competence and cultural competence especially the knowledge of genre plays very important role in producing a piece of writing. The contribution of each element of language competence and writing competence can be summarized in the following diagram 2:

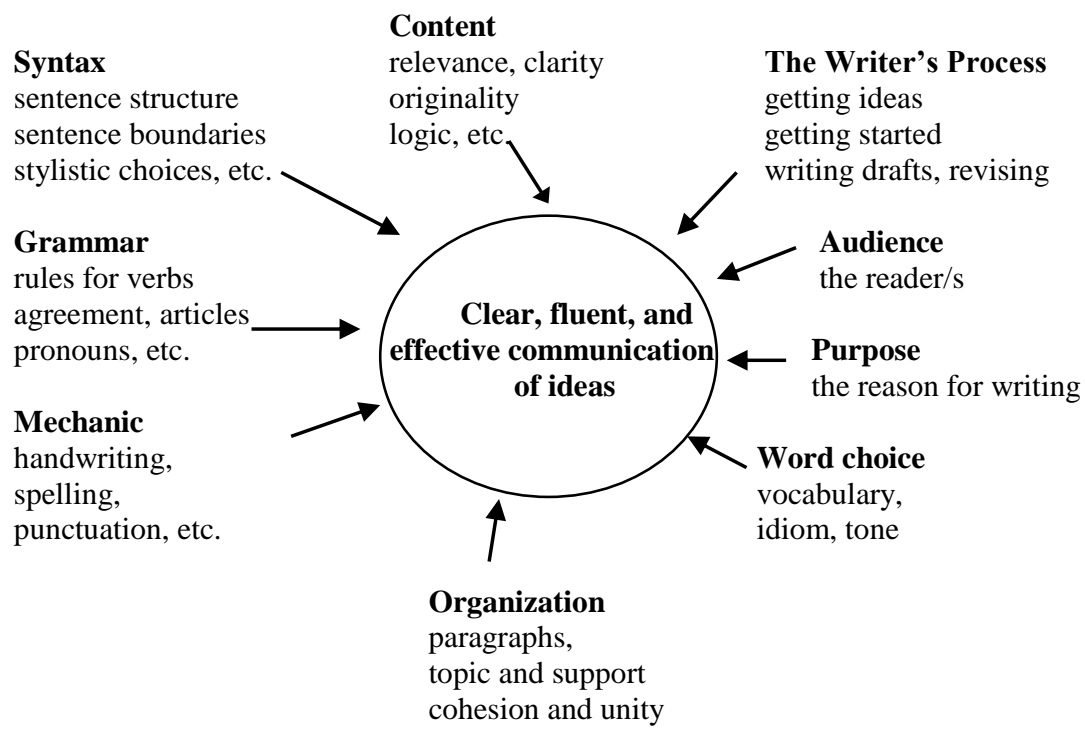

Diagram 2. Producing a piece of writing Raimes (1983)

As we can see in Diagram 2, a good piece of writing which is basically representation of clear, fluent, and effective communication of ideas is very much influenced by many elements that can be broadly categorized into three, namely language competence, writing competence, and cultural competence.

From the diagram, it is obvious that elements such as syntax, grammar, and word choice belong to language competence. While the elements that belong to the writing competence are those like the writer's process, content, mechanic and organization. The rest which includes audience, purpose as well as content are elements which belong to cultural competence.

The mastery of each of these elements is basic in writing. Therefore, teacher must know these elements and apply them in their practice of teaching writing to his/her students. These elements are equally important and interdependent in contributing to the production of a good piece of writing. 
Teacher is expected to encourage their students to produce a piece of composition by giving great consideration on these elements. This can be done effectively through recursive process where the students may go back to their previous steps whenever they are not sure about any elements in their composition.

The way the writing task can completed is outlined in diagram 3 . The diagram shows that for any writing task which function to fulfill communicative task within certain context, a successful writer draws on knowledge of the genre (content and context), knowledge of the language system, and knowledge of appropriate writing processes.

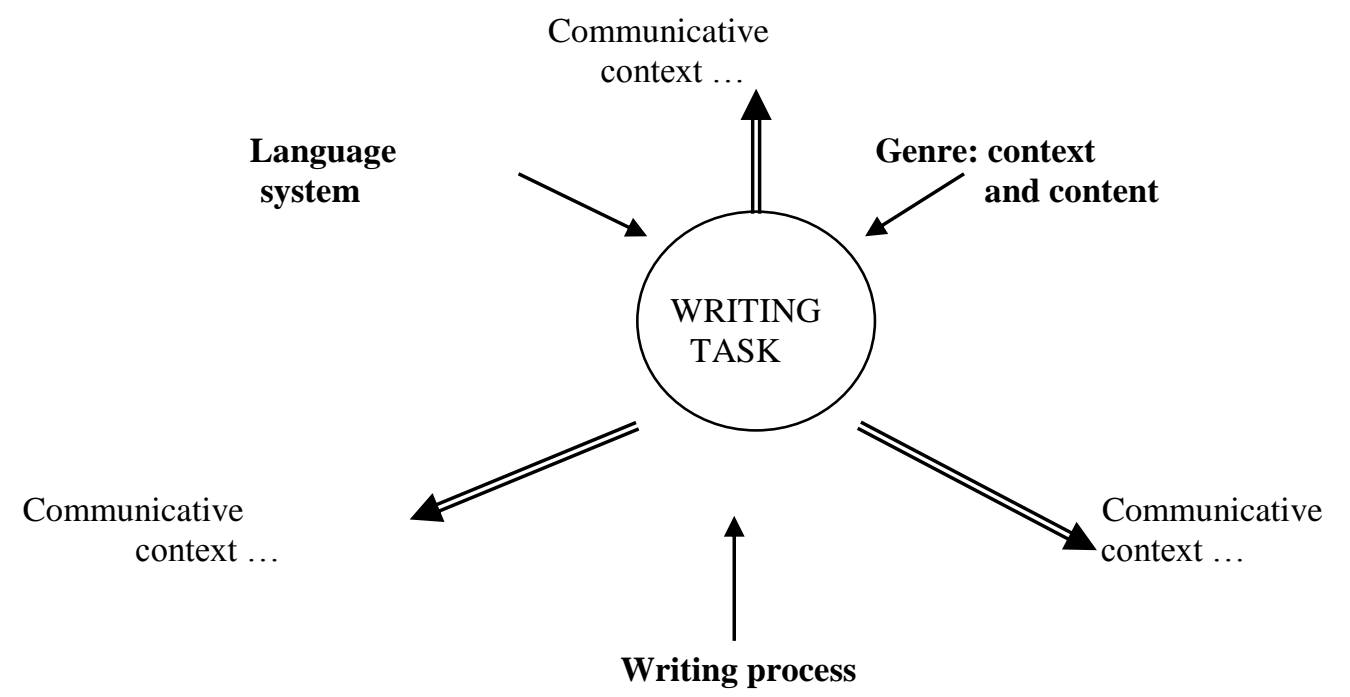

Diagram 3. Interrelation among language system, writing process and genre

\section{Conclusion}

In order to produce a successful and effective piece of writing, a writer is much influenced by three important elements of writing which are interrelated one to another. These elements include language competence, writing competence and cultural competence. These kinds of competence should be understood by writing teacher and transferred to his/her students. It is expected that the mastery of these writing elements by the students along with their implementation through recursive writing process will make the students easy to produce a good piece of writing. 


\section{Reference}

Brown, H.D. 2001. Teaching by Principles, An Interactive Approach to Language Pedagogy. Longman.

Kramsch, Claire. 1992. Context and culture in language teaching. Oxford University Press

Leon \& Harry Potter.Language Competence in http://efl.htmlplanet.com/langcomp.htm, retrieved May 23, 2007

Liddicoat, Anthony. 1997. Communicating within cultures, communicating across cultures, communicating between culture. Academic communication across disciplines and cultures. Victoria University of Technology Australia

Malinowski, B. 1960. A scientific theory of culture and other essays (second edition). New York, Oxford University Press

Modern Classical Language 2005. What is Language Competence. Board of Governors, Missouri State University in http://www.missouristate.edu/vlc/languagelearning/competence.asp, retrieved May 23, 2007

Oring, E. 1986. Folk groups and folk genre. Utah State University Press

Raimes, Ann. 1983. Techniques in Teaching Writing. Oxford University Press

Tribble, C. 1996. Writing. Oxford University Press

Whiteman, M.F. Writing: The Nature, Development, and Teaching of Written communication. Lawrence Erlbaum Associates Publisher. 